\title{
Digitoxin synergizes with sorafenib to inhibit hepatocelluar carcinoma cell growth without inhibiting cell migration
}

\author{
YIJUN XIAO ${ }^{1}$, WEI YAN ${ }^{1}$, LIBIN GUO ${ }^{1,2}$, CHEN MENG $^{1}$, BIN $^{2}{ }^{2}$, HENRIQUE NEVES $^{2}$, \\ PENG-CHEN CHEN ${ }^{1}$, LING LI ${ }^{3}$, YIDE HUANG ${ }^{1}$, HANG FAI KWOK $^{2}$ and YAO LIN ${ }^{1}$ \\ ${ }^{1}$ College of Life Sciences, Fujian Normal University, Fuzhou, Fujian; \\ ${ }^{2}$ Faculty of Health Sciences, University of Macau, Avenida de Universidade, Taipa, Macau SAR; \\ ${ }^{3}$ The United Innovation of Mengchao Hepatobiliary Technology Key Laboratory of Fujian Province, \\ Mengchao Hepatobiliary Hospital of Fujian Medical University, Fuzhou, Fujian, P.R. China
}

Received December 8, 2015; Accepted November 24, 2016

DOI: $10.3892 / \mathrm{mmr} .2016 .6096$

\begin{abstract}
Sorafenib is a chemotherapeutic agent approved for the treatment of hepatocellular carcinoma (HCC) in China. Digitoxin is a cardiotonic drug, which has been demonstrated to exhibit anticancer effects in a number of cancers, but not in HCC. The aim of the present study was to evaluate the combinational effect of sorafenib and digitoxin on the treatment of HCC and to investigate the relevant molecular mechanisms of action that underlie these effects. The proliferation, cell death and migration of HCC cell lines, HepG2 and BEL-7402, were examined using MTT, acridine orange/ethidium bromide staining and scratch wound healing assays, respectively. In addition, alterations in the expression of phosphorylated-extracellular signal-regulated kinase (ERK), hypoxia-inducible factor $1-\alpha$ (HIF-1 $\alpha$ ), hypoxia-inducible factor $2-\alpha$ (HIF-2 $\alpha$ ) and vascular endothelial growth factor (VEGF) were measured prior to and following drug application using western blot analysis. Digitoxin and sorafenib synergistically inhibited cell viability, but did not inhibit migration, which was potentially mediated by suppression of ERK and hypoxia signaling. In downstream signaling pathways, the activity of ERK was synergistically suppressed by combinatorial treatment of HepG2 and BEL-7402 cells with sorafenib and digitoxin. In addition, the expression of HIF-1 $\alpha$, HIF- $2 \alpha$ and VEGF was synergistically downregulated by combinational treatment.
\end{abstract}

Correspondence to: Professor Yao Lin, College of Life Sciences, Fujian Normal University, 10 Ligong Building, Fuzhou, Fujian 350117, P.R. China

E-mail: yaolin@fjnu.edu.cn

Professor Hang Fai Kwok, Faculty of Health Sciences, University of Macau, Avenida de Universidade, Taipa, Macau SAR, P.R. China

E-mail: hfkwok@umac.mo

Key words: hepatocellular carcinoma, sorafenib, digitoxin, synergistic inhibition

\section{Introduction}

Hepatocellular carcinoma (HCC) is the most common form of liver cancer and the third most lethal cancer worldwide (1). Over 500,000 new cases of HCC are diagnosed each year worldwide, with $\sim 50 \%$ of cases diagnosed in China alone (2). Multiple gene mutations, insertion of viral DNA and epigenetic alterations are involved in the genetic mechanisms underlying hepatocarcinogenesis (3). Surgery is currently the primary approach for the treatment of HCC; however, a consistent effective chemotherapeutic option for this disease is required (1).

Sorafenib is a small molecule inhibitor that targets multiple kinases, including Raf kinases, the vascular endothelial factor receptor and the platelet-derived growth factor receptor, and is approved for the treatment of advanced HCC in Chinese clinics (4). The efficacy of sorafenib for the improvement of median survival rates was first presented in 2008 (5). Following this, sorafenib was identified as useful for the treatment of HCC in several additional studies, either alone or in combinational treatment $(6,7)$. However, unsatisfactory response rates and adverse side effects, such as diarrhea and jaundice, have been reported (8). The search for an efficient adjuvant agent to sorafenib has recently invited significant attention in the field.

Digitoxin is a cardiac glycoside that has been widely studied and used for its cardiotonic effects (9). Since the 1990s, the anticancer effect of digitoxin has been demonstrated in multiple cancer types including prostate, breast and pancreatic cancers $(10,11)$. However, the precise anticancer mechanisms of digitoxin remain elusive. It has been proposed that, at nanomolar concentrations, digitoxin activates the $\mathrm{Na}^{+} / \mathrm{K}^{+}$adenosine triphosphatase signalosome to regulate cellular events, including apoptosis, cell movement, cell proliferation and tight junction regulation (10). Signaling pathways, including the p53, mitogen-activated protein kinase/extracellular signal-regulated kinase (ERK) and phosphatidyl-inositol-3-kinase pathways, have been demonstrated to be affected by digitoxin (10). As the target downstream signaling pathways of digitoxin overlap with those targeted by sorafenib, and the activity of digitoxin on HCC has not yet 
been reported, the combination of these drugs may provide a novel treatment strategy for HCC. Therefore, the aim of the present study was to investigate the effects of the combinational treatment of digitoxin and sorafenib on HCC cells, and to examine the relevant underlying molecular mechanisms.

\section{Materials and methods}

Cell culture. Human HCC cell lines BEL-7402 and HepG2 were purchased from the Shanghai Institute of Biochemistry and Cell Biology (Chinese Academy of Sciences, Shanghai, China). These cell lines were maintained in Dulbecco's Modified Eagle's medium (Invitrogen; Thermo Fisher Scientific, Inc., Waltham, MA, USA) containing $10 \%$ fetal bovine serum (Equitech-Bio, Kerrville, Texas, USA), 100 U/ml penicillin $\mathrm{G}$ and $100 \mathrm{Ug} / \mathrm{ml}$ streptomycin (Invitrogen; Thermo Fisher Scientific, Inc.). Digitoxin was purchased from Sigma-Aldrich; Merck-Millipore (Darmstadt, Germany). Sorafenib was purchased from Bayer AG (Leverkusen, Germany). Cells were treated with different concentrations of digitoxin $(0,10,20,40,80$ and $160 \mathrm{nmol} / \mathrm{l})$ and with various concentrations of sorafenib $(0,1,2,4,8$ and $16 \mu \mathrm{mol} / \mathrm{l})$ prior to the MTT assay. For wound healing assays, western blot analyses and the acridine orange/ethidium bromide (AO/EB) assay, the cells of control group cultured in RPMI 1640 medium (Invitrogen; Thermo Fisher Scientific, Inc.), whereas cells in the experimental groups were treated with $10 \mathrm{nmol} / \mathrm{l}$ digitoxin and $8 \mu \mathrm{mol} / 1$ sorafenib.

MTT assay. A total of 5,000 cells were seeded in a 96-well plate in $200 \mu \mathrm{l}$ medium and incubated for 24,48 and $72 \mathrm{~h}$ at $37^{\circ} \mathrm{C}$ in $5 \% \mathrm{CO}_{2}$ incubator. Cell viability was determined using an MTT assay kit (cat. no. 0793; Amresco, LLC, Solon, $\mathrm{OH}$, USA) according to the manufacturer's instructions. The absorbance was read at $490 \mathrm{~nm}$ on a microplate reader (BioTek Instruments, Inc., Winooski, VT, USA). All assays were performed in triplicate. For statistical analysis of cell viability, one-way analysis of variance with the Dunnett's post-hoc test was used.

Scratch wound healing assay. HepG2 and BEL-7402 cells were seeded in a six-well plates at a density of $2 \times 10^{3}$ cells/well and incubated overnight until they reached confluency. The monolayer of cells were scratched with a sterile pipette tip to create a wound. Cells were washed twice with serum-free media to remove floating cells, and cultured in complete media containing serum. Three groups of cells were treated with digitoxin and/or sorafenib, while the control group was left untreated. The cells migrating from the leading edge were imaged at 0 and $48 \mathrm{~h}$. A total of three fields of view for each well were analyzed and experiments were performed in triplicate. The migration index was calculated using the following formula: Migration index $=\left(\mathrm{g}_{0 \mathrm{~h}}-\mathrm{g}_{48 \mathrm{~h}}\right) / \mathrm{g}_{0 \mathrm{~h}} \times 10$ $0 \%$, where $\mathrm{g}_{0 \mathrm{~h}}$ and $\mathrm{g}_{48 \mathrm{~h}}$ represent the wound width at 0 and $48 \mathrm{~h}$, respectively.

Western blot analysis. BEL-7402 and HepG2 cells were exposed to sorafenib $(8 \mu \mathrm{M})$ and/or digitoxin $(10 \mathrm{nM})$ for 24 or $48 \mathrm{~h}$ prior to western blot analysis. A total of $\sim 1 \times 10^{6}$ cells were homogenized in 100-200 $\mu 1$ radioimmunoprecipitation assay lysis buffer (Beyotime Institute of Biotechnology, Haimen, China) containing protease inhibitors (Roche Diagnostics, Basel, Switzerland) at $4^{\circ} \mathrm{C}$ for $30 \mathrm{~min}$ prior to western blot analysis, as described previously (12). The polyvinylidene difluoride (PVDF) membranes were incubated for $2 \mathrm{~h}$ at $37^{\circ} \mathrm{C}$ or overnight at $4^{\circ} \mathrm{C}$ with the following primary antibodies (dilution, 1:500): Anti-p44/42 (ERK; cat no. 9102; Cell Signaling Technology, Inc., Danvers, MA, USA), anti-phosphorylated (p)-p44/42 ERK (cat. no. sc-16982; Santa Cruz Biotechnology, Inc., Dallas, TX, USA), anti-vascular endothelial growth factor (VEGF; cat no. sc-4570; Santa Cruz Biotechnology, Inc.), anti-hypoxia inducible factor (HIF)-1 $\alpha$ (cat. no. MA-516; Thermo Fisher Scientific, Inc.), anti-HIF-2 $\alpha$ (cat. no. ab8365; Abcam, Cambridge, UK) and anti- $\beta$-actin (cat. no. 4970; Cell Signaling Technology, Inc.). The horseradish peroxidase-conjugated goat anti-rabbit IgG (cat. no. 12-348) and goat anti-mouse IgG (cat. no. 12-349) secondary antibodies were purchased from Sigma-Aldrich; Merck Millipore. The PVDF membranes were incubated with the secondary antibodies (dilution, 1:5,000) for $1 \mathrm{~h}$ at $37^{\circ} \mathrm{C}$. Protein bands were detected using an enhanced chemiluminescence kit (Thermo Fisher Scientific Inc.) and were detected by Chemic Genius Bioimaging System (Syngene, Frederick, MD). GeneSnap (version, 7.12) and GeneTools (version, 4.3.5) software programs (Syngene) were used for quantification.

$A O / E B$ assay. Cells were seeded in six-well plates to a final concentration of $2 \times 10^{5}$ cells/well. Following $24 \mathrm{~h}$, cells were exposed to digitoxin $(10 \mathrm{nmol} / \mathrm{l})$ and/or sorafenib $(8 \mu \mathrm{mol} / \mathrm{l})$ for $48 \mathrm{~h}$ at $37^{\circ} \mathrm{C}$ in $5 \% \mathrm{CO}_{2}$, before they were stained with $\mathrm{AO} / \mathrm{EB}$ dye mixture containing AO $(200 \mu \mathrm{g} / \mathrm{ml}$; Sigma-Aldrich; Merck Millipore) and EB (200 $\mu \mathrm{g} / \mathrm{ml}$; Sino-American Biotechnology Company, Luoyang, China). A total of six fields of view for each group were observed and counted under a fluorescence microscope (Nikon Corporation, Tokyo, Japan).

Statistical analysis. Statistical analysis and visualization of the data was achieved using the GraphPad Prism software program (version, 6.04; GraphPad Software Inc., La Jolla, CA, USA) and the Bliss additive model (13). The Bliss additive model was used to classify the effects of combining digitoxin and sorafenib as additive, synergistic or antagonistic. Combined inhibition was calculated using the following equation: Ebliss = EA + EB - EA x EB, where EA and EB represent the fractional inhibitions obtained by drug $\mathrm{A}$ (digitoxin) alone and drug B (sorafenib) alone at specific concentrations. Data were analyzed using the Student's $t$-test and one-way analysis of variance with the Dunnett's post-hoc test. Samples were analyzed in triplicate, and experiments were repeated three times. $\mathrm{P}<0.05$ was considered to indicate a statistically significant difference.

\section{Results}

Sorafenib and digitoxin synergized to suppress the viability, but not migration of HCC cells. The effect of a range of concentrations of sorafenib $(0,1,2,4,8$ and $16 \mu \mathrm{M})$ and digitoxin $(0,10,20,40,80$ and $160 \mathrm{nM})$ on the viability of HCC cells was first examined using an MTT assay. For 

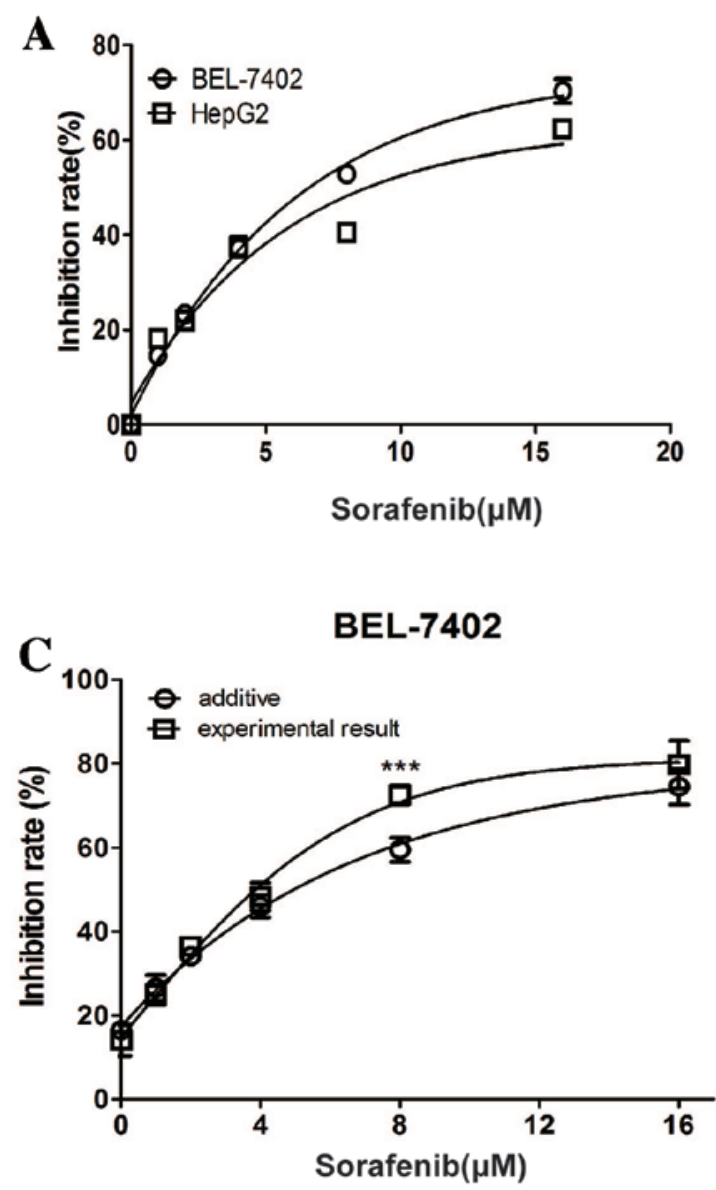
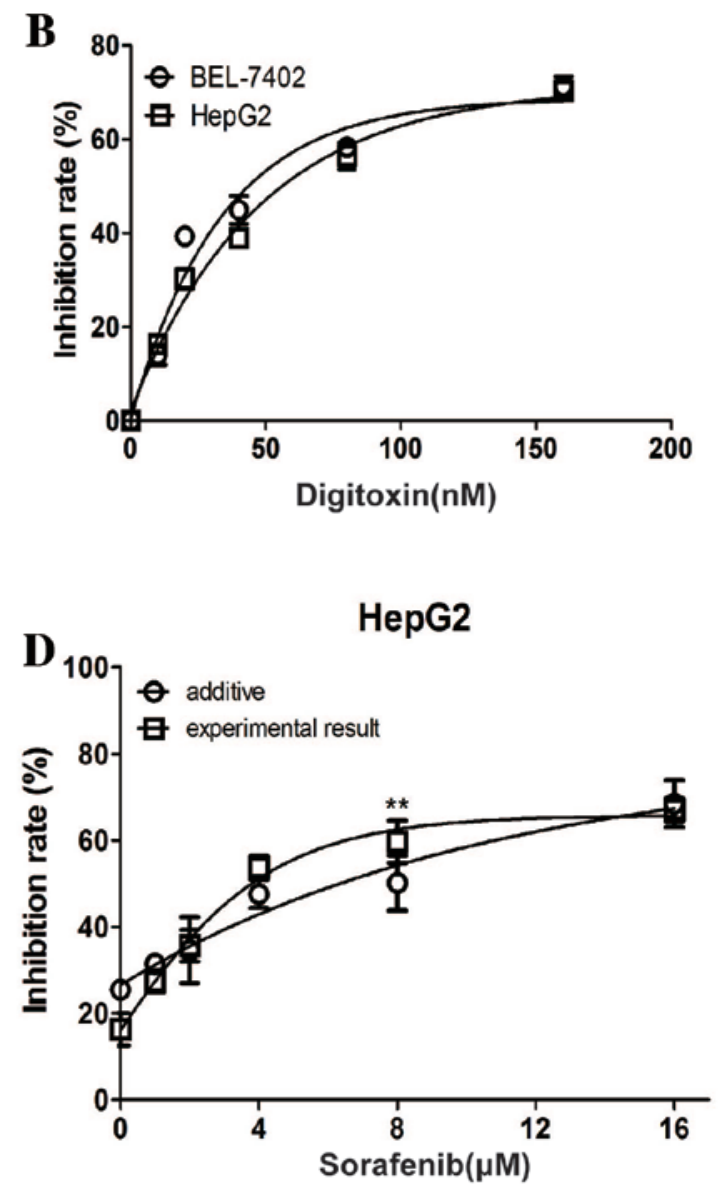

Figure 1. Sorafenib and digitoxin synergistically-inhibits the proliferation of hepatocellular carcinoma cell lines. BEL-7402 and HepG-2 cells were exposed to a series of concentrations of (A) sorafenib $(0,1,2,4,8$ and $16 \mu \mathrm{M})$ or (B) digitoxin $(0,10,20,40,80$ and $160 \mathrm{nM})$ for $48 \mathrm{~h}$ prior to MTT assay analysis. (C) BEL-7402 and (D) HepG-2 cells were exposed to a series of concentrations of sorafenib $(0,1,2,4,8$ and $16 \mu \mathrm{M})$ in combination with digitoxin (10 nM) for $48 \mathrm{~h}$ prior to MTT assay analysis. The additive inhibition for each combination was calculated using the Bliss additive model. Each experiment was performed in triplicate, and data are presented as the mean \pm standard error. ${ }^{* *} \mathrm{P}<0.01$ and ${ }^{* * *} \mathrm{P}<0.001$ vs. additive.

the BEL-7402 and HepG2 cells, the half maximal inhibitory concentration values for sorafenib were $\sim 8 \mu \mathrm{M}$ and for digitoxin were $\sim 80 \mathrm{nM}$ (Fig. 1A and B). Considering the high cardiotoxicity of digitoxin in clinical practice (14) and the recent model demonstrating that digitoxin is sufficient to activate intracellular downstream signaling cascades at $10 \mathrm{nM}(10)$, the effect of sorafenib in combination with a low concentration of digitoxin $(10 \mathrm{nM})$ on HCC cells was examined in the present study. Sorafenib $(8 \mu \mathrm{M})$ and digitoxin $(10 \mathrm{nM})$ significantly inhibited the viability of BEL-7402 and HepG 2 cells $(\mathrm{P}<0.001$ and $\mathrm{P}<0.01$, respectively; Fig. $1 \mathrm{C}$ and D) when compared with the established additive combinatorial inhibition that was based on single agent data and the Bliss additive model. This suggests a synergy between the two reagents at these concentrations.

$\mathrm{AO} / \mathrm{EB}$ staining was then used to examine cell death (Fig. 2A and B). Consistent with the MTT assay results, the death rate of BEL-7402 and HepG2 cells exposed to $8 \mu \mathrm{M}$ sorafenib plus $10 \mathrm{nM}$ digitoxin was significantly higher when compared with the additive cell death rate $(\mathrm{P}=0.041$ and $\mathrm{P}=0.0057$, respectively; Fig. 2C). In addition to cell death, cell migration of VSMC and NSCLC has been demonstrated to be affected by digitoxin treatment, while the effect of digitoxin on migration of hepatocellular carcinoma cell is still unknown $(15,16)$. Sorafenib has been reported to inhibit migration of hepatocellular carcinoma cells (17). Therefore, the present study investigated the effect of sorafenib and digitoxin on cell migration using a scratch wound healing assay (Fig. 3A and B). Although the cell migration inhibition, generated by $8 \mu \mathrm{M}$ sorafenib was enhanced in BEL-7402 and HepG2 cells, when cells were exposed to sorafenib plus $10 \mathrm{nM}$ digitoxin, a significant increase in cell migration was observed when compared with the additive inhibition. This suggests that sorafenib and digitoxin antagonized each other in cell migration suppression (Fig. 3C).

Sorafenib plus digitoxin treatment inhibited the ERK and hypoxia responsive pathways. ERK is an important downstream effector of Raf kinases, and is affected by digitoxin (18). Therefore, the present study examined the expression of p-ERK in HCC cells exposed to $8 \mu \mathrm{M}$ sorafenib and/or $10 \mathrm{nM}$ digitoxin. $\mathrm{p}$-ERK expression inhibition was more efficient in BEL-7402 and HepG2 cells treated with sorafenib plus digitoxin, when compared with either agent alone (Fig. 4). Previous studies have demonstrated that HIF-1 $\alpha$, HIF- $2 \alpha$ and VEGF are therapeutic targets of either digitoxin or sorafenib in several cancer types $(19,20)$. As a result, the expression of these proteins in cells exposed to 
A
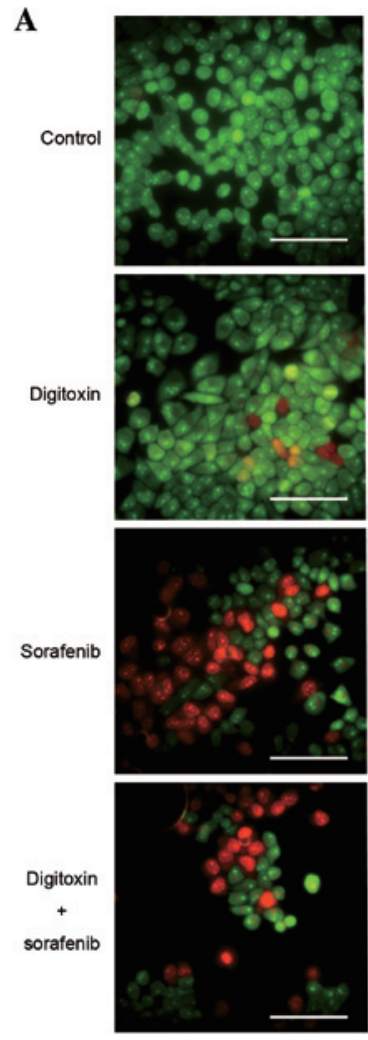

C

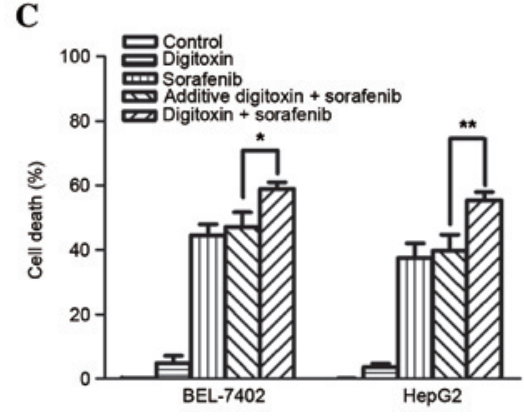

Figure 2. Sorafenib and digitoxin synergized to induce cell death of hepatocellular carcinoma cell lines. (A) BEL-7402 and (B) HepG-2 cells were exposed to sorafenib $(8 \mu \mathrm{M})$ and/or digitoxin $(10 \mathrm{nM})$ for $48 \mathrm{~h}$ prior to acridine orange/ethidium bromide staining (scale bar, $50 \mu \mathrm{m}$ ). Experiments were performed in triplicate. (C) Cell death was quantified as the percentage of red cells out of the total number of cells. The additive cell death induction was calculated using the Bliss additive model. Data are presented as the mean \pm standard error. ${ }^{*} \mathrm{P}<0.05$ vs. Additive digitoxin + sorafenib in BEL-7402 cells; * $\mathrm{P}<0.01$ vs. Additive digitoxin + sorafenib in HepG-2 cells.

sorafenib and/or digitoxin was examined in the present study. Similar to p-ERK expression, greater suppression of HIF- $1 \alpha$, HIF- $2 \alpha$ and VEGF expression was observed following treatment of cells with sorafenib plus digitoxin, when compared to application with either agent alone (Fig. 5).

\section{Discussion}

The development of novel anticancer agents is a long and expensive process, which is often associated with a high failure rate $(21,22)$. Drugs that have already been approved for the treatment of other diseases in the clinic, may be tested for their anticancer properties more rapidly and with less expense. This
$\mathbf{A}$

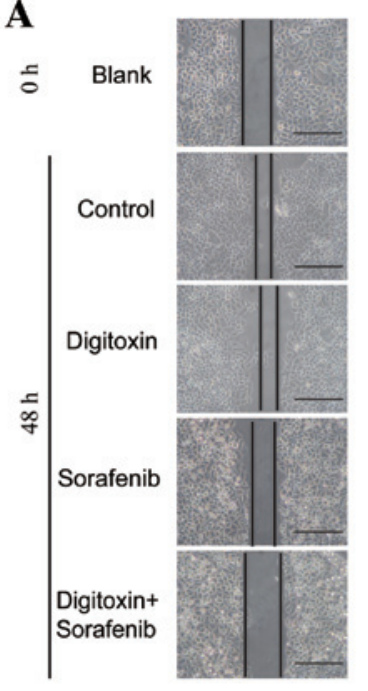

B

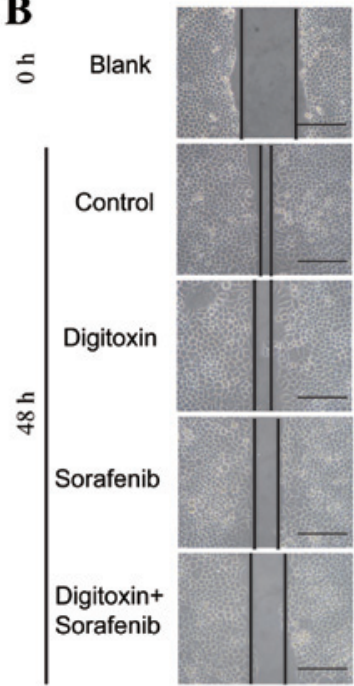

C

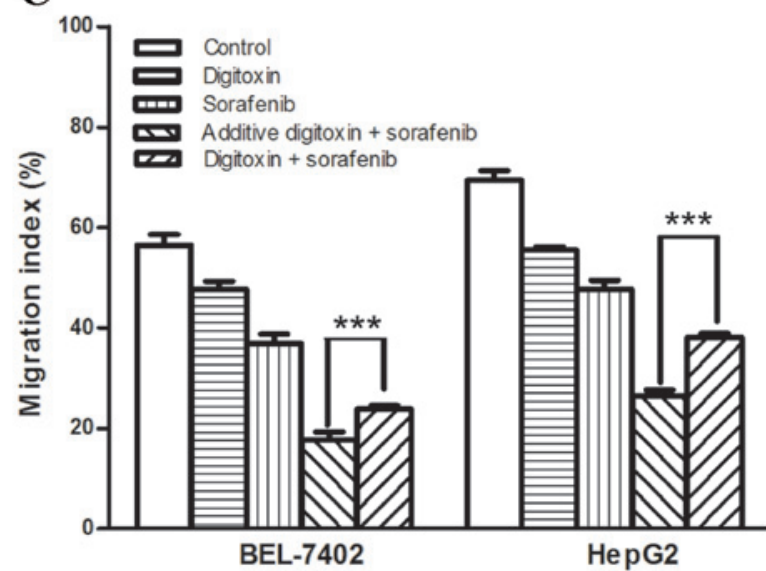

Figure 3. Sorafenib and digitoxin synergized to suppress the migration of hepatocellular carcinoma cell lines. (A) BEL-7402 and (B) HepG-2 cells were exposed to sorafenib $(8 \mu \mathrm{M})$ and/or digitoxin $(10 \mathrm{nM})$ and subject to a scratch wound healing assay (scale bar, $50 \mu \mathrm{m}$ ). The wound status was recorded at $0 \mathrm{~h}$ and $48 \mathrm{~h}$ post-scratch. Experiments were performed in triplicate. (C) The migration index was quantified as the percentage change in wound width at $48 \mathrm{~h}$ vs. $0 \mathrm{~h}$. The additive migration index was calculated using the Bliss additive model. Data are presented as the mean \pm standard error. ${ }^{* * *} \mathrm{P}<0.001$ vs. additive digitoxin + sorafenib.

process of drug 'repurposing' has the potential of accelerating anticancer drug development. For instance, the anticancer properties of the rheumatoid arthritis drug auranofin (23) or the oral hypoglycemic agent metformin (24) have recently been discovered, and clinical trials investigating the application of these drugs in cancer treatment are currently ongoing. As it has been studied for a number of years, the clinical profile of digitoxin is already well established (25), which may facilitate the rapid initiation of clinical trials investigating its effectiveness in combination with sorafenib. Therefore, digitoxin represents an attractive adjuvant agent. The anticancer effects of digitoxin have been understood for decades (26); however, its narrow therapeutic window caused by high cardiotoxicity, hinders its application in cancer as a single agent. The present study demonstrated that, even at a very low concentration $(10 \mathrm{nM})$, digitoxin is sufficiently potent to synergize with sorafenib to initiate cell death, which suggests that it may be a promising 
A

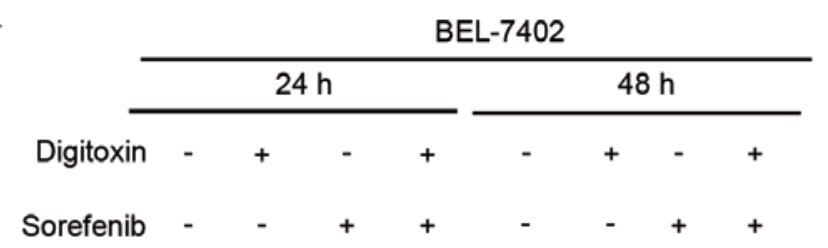

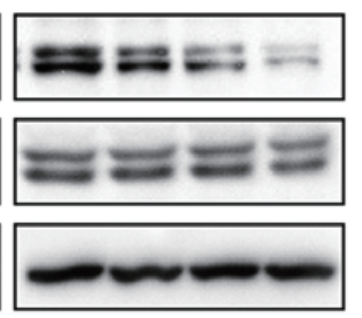

HepG2

\begin{tabular}{|c|c|c|c|c|c|c|c|}
\hline \multicolumn{4}{|c|}{$24 \mathrm{~h}$} & \multicolumn{4}{|c|}{$48 \mathrm{~h}$} \\
\hline - & + & - & + & - & + & - & + \\
\hline - & - & + & + & - & - & + & + \\
\hline
\end{tabular}
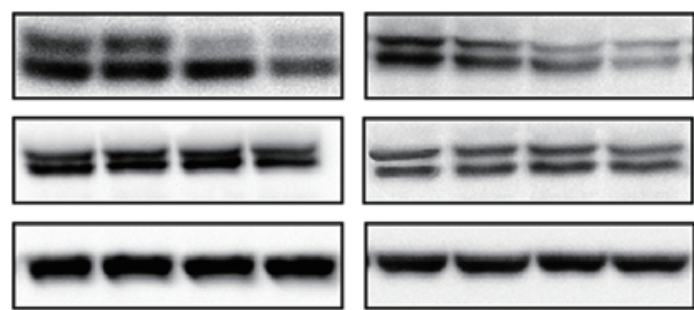

B

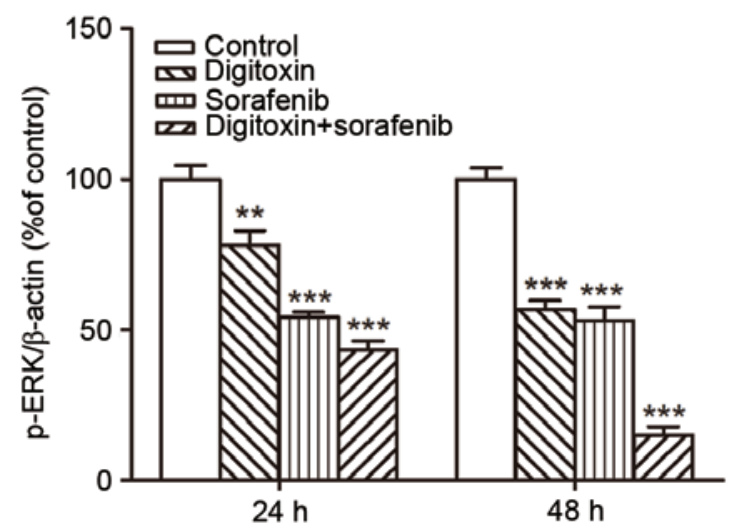

C

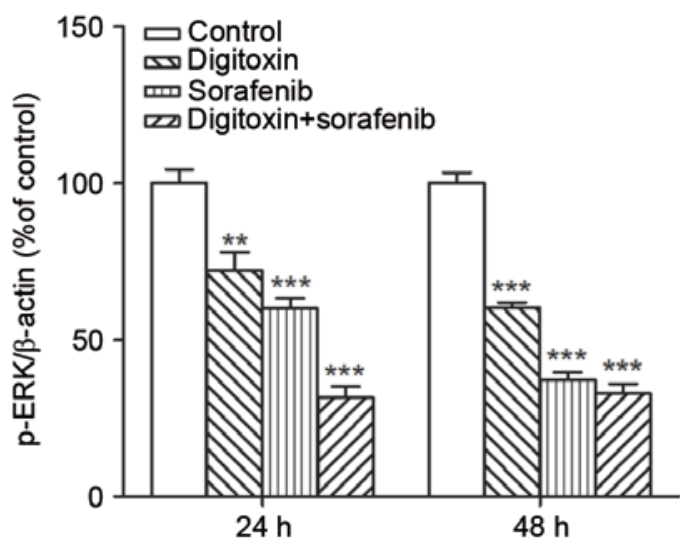

Figure 4. Sorafenib and digitoxin synergized to inhibit ERK protein levels in hepatocellular carcinoma cell lines. (A) BEL-7402 and HepG2 cells were exposed to sorafenib $(8 \mu \mathrm{M})$ and/or digitoxin $(10 \mathrm{nM})$ for 24 or $48 \mathrm{~h}$ prior to western blot analysis. Experiments were performed in duplicate and GeneTools software (Syngene) was used for quantification. Quantification of the protein expression levels of p-ERK, ERK and $\beta$-actin in (B) BEL-7402 and (C) HepG2 cells. ${ }^{* * *} \mathrm{P}<0.01$ and ${ }^{* * * *} \mathrm{P}<0.001$ vs. control. p-ERK, phosphorylated extracellular signal-regulated kinase.

candidate for combinational treatment with sorafenib for HCC. However, sorafenib was not observed to synergize with digitoxin in the cell migration assay indicating that the synergy primarily relied on the signaling pathways associated with cell death Future studies will aim to explore these effects in vivo using animal models to further validate these results.

In response to the sorafenib and/or digitoxin treatment, the expression alterations of four signaling proteins, $\mathrm{p}$-ERK, HIF- $1 \alpha$, HIF- $2 \alpha$ and VEGF, were examined. In single agent treatment, sorafenib suppressed HIF-1 $\alpha$ and HIF- $2 \alpha$ expression more than digitoxin in the cell lines examined. Considering the difference in cell death induction between $10 \mathrm{nM}$ digitoxin and $8 \mu \mathrm{M}$ sorafenib, it is possible that the hypoxia pathway may be more critical for cell viability among the four proteins tested in HCC. Conversely, the expression changes of ERK and VEGF coincides better with cell migration alterations, which suggests they may be more involved in regulating cell migration in HCC.

The results of the present study demonstrated that sorafenib in combination with digitoxin suppresses HCC cell viability, which may be mediated through inhibition of p-ERK, HIF-1 $\alpha$, HIF- $2 \alpha$ and VEGF expression. This is consistent with the findings of a previous study demonstrating that digitoxin exhibits greater toxicity in lung cancer cells when compared with primary or non-tumorigenic epithelial cells (27). However whether this selectivity remains in patients with HCC, is unknown. Toxicity in normal liver epithelial cells will need to be taken into account in future in vivo or in vitro experiments, when evaluating the effectiveness of combined sorafenib and digitoxin treatment.

\section{Acknowledgements}

The present study was fully supported by the National Natural Science Foundation of China for Distinguished Young Scholars (grant nos. 31301172 and 31201008), the Natural Science Foundation of Fujian Province (grant no. 2014J01122), the Scientific Foundation of Fuzhou University (grant no. 2014-S-139-7), the Open Scientific Foundation of Fujian Key Laboratory (grant no. 2014ZDSY2002) and was partially supported from the University of Macau Start-Up Research Grant (grant no. SRG2014-00006-FHS) \& Multi-Year Research Grant (grant no. MYRG2015-00065-FHS). Ms. Libin Guo, Ms. Bin Li and Mr. Henrique Neves are in receipt of $\mathrm{PhD}$ studentships from the Faculty Health Sciences University of Macau. 
A
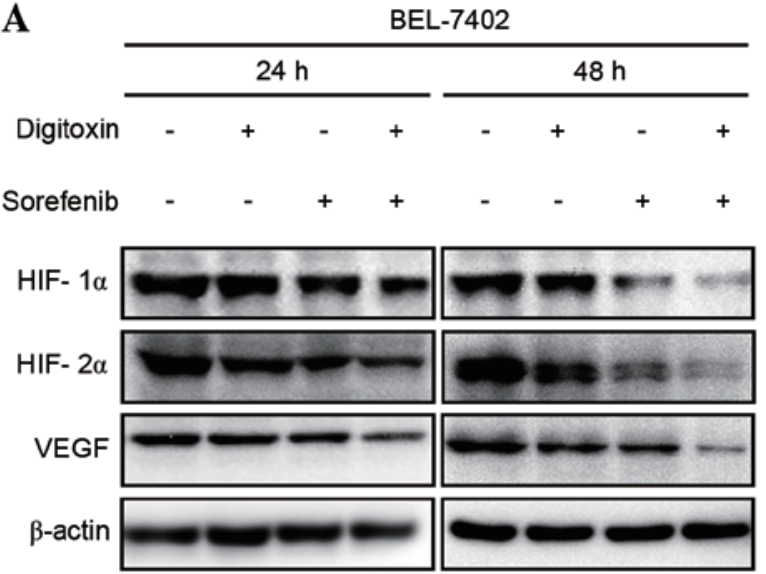
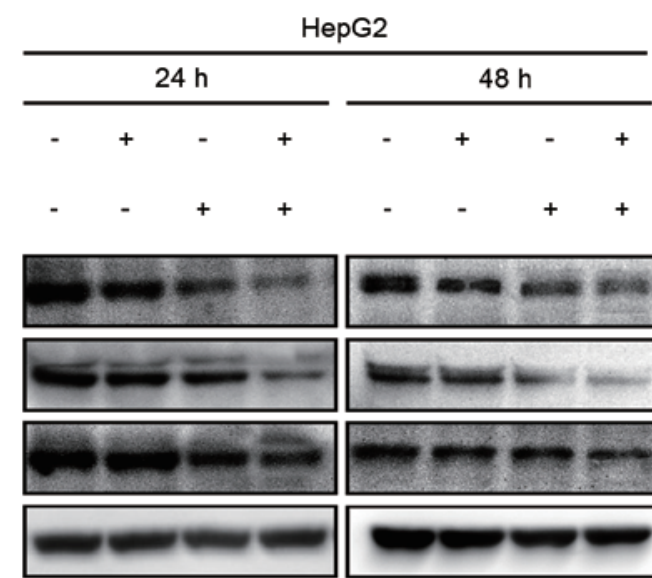

B
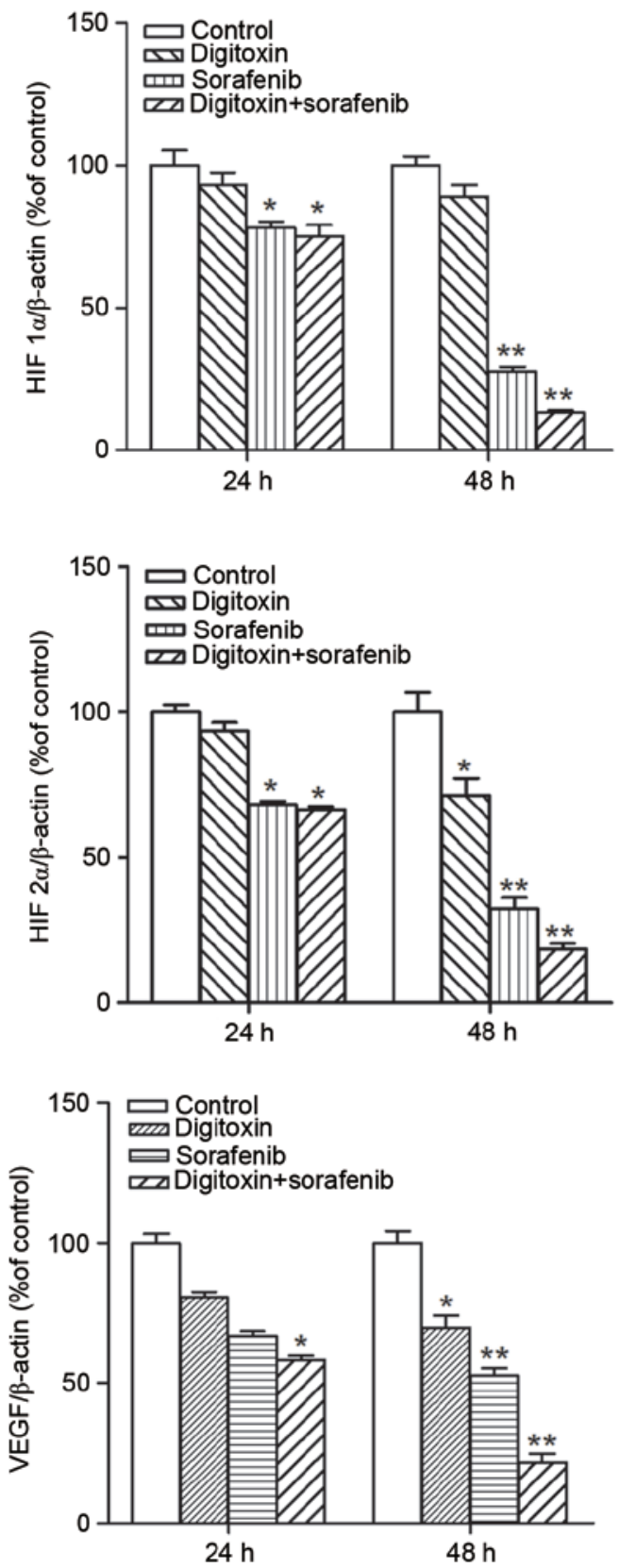

$\mathbf{C}$
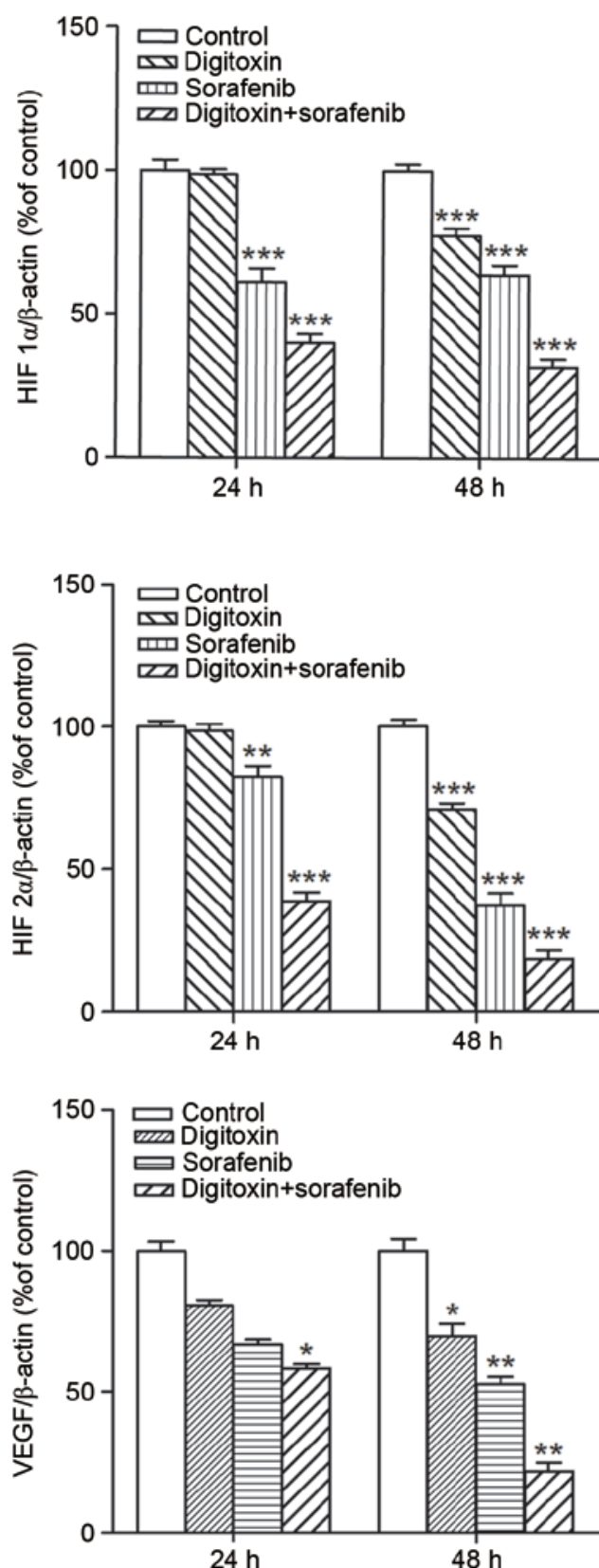

Figure 5. Sorafenib and digitoxin synergized to suppress the hypoxia signaling pathway in hepatocarcinoma cell lines. (A) BEL-7402 and HepG2 cells were exposed to sorafenib $(8 \mu \mathrm{M})$ and/or digitoxin $(10 \mathrm{nM})$ for 24 or $48 \mathrm{~h}$ prior to western blot analysis. These experiments were performed in duplicate and the GeneTools software program (Syngene) was used for quantification. The expression of HIF-1 $\alpha$, HIF-2 $\alpha$, VEGF and $\beta$-actin were identified in (B) BEL-7402 and (C) HepG2 cells. ${ }^{*} \mathrm{P}<0.05,{ }^{* *} \mathrm{P}<0.01$ and ${ }^{* * *} \mathrm{P}<0.001$ vs. control. HIF, hypoxia-inducible factor; VEGF, vascular endothelial growth factor. 


\section{References}

1. El-Serag HB: Hepatocellular Carcinoma. N Engl J Med 365: 1118-1127, 2011

2. Jemal A, Bray F, Center MM, Ferlay J, Ward E and Forman D: Global cancer statistics. CA Cancer J Clin 61: 69-90, 2011.

3. Feitelson MA, Sun B, Satiroglu Tufan NL, Liu J, Pan J and Lian Z: Genetic mechanisms of hepatocarcinogenesis. Oncogene 21: 2593-2604, 2002.

4. Wilhelm SM, Carter C, Tang L, Wilkie D, McNabola A, Rong H, Chen C, Zhang X, Vincent P, McHugh M, et al: BAY 43-9006 exhibits broad spectrum oral antitumor activity and targets the $\mathrm{RAF} / \mathrm{MEK} / \mathrm{ERK}$ pathway and receptor tyrosine kinases involved in tumor progression and angiogenesis. Cancer Res 64 7099-7109, 2004.

5. Llovet JM, Ricci S, Mazzaferro V, Hilgard P, Gane E, Blanc JF, de Oliveira AC, Santoro A, Raoul JL, Forner A, et al: Sorafenib in advanced hepatocellular carcinoma. N Engl J Med 359: 378-390, 2008.

6. Pawlik TM, Reyes DK, Cosgrove D, Kamel IR, Bhagat N and Geschwind JF: Phase II trial of sorafenib combined with concurrent transarterial chemoembolization with drug-eluting beads for hepatocellular carcinoma. J Clin Oncol 29: 3960-3967, 2011.

7. Keating GM and Santoro A: Sorafenib: A review of its use in advanced hepatocellular carcinoma. Drugs 69: 223-240, 2009.

8. Cheng AL, Kang YK, Chen Z, Tsao CJ, Qin S, Kim JS, Luo R, Feng J, Ye S, Yang TS, et al: Efficacy and safety of sorafenib in patients in the Asia-Pacific region with advanced hepatocellular carcinoma: A phase III randomised, double-blind, placebo-controlled trial. Lancet Oncol 10: 25-34, 2009.

9. Belz G, Breithaupt-Grögler K and Osowski U: Treatment of congestive heart failure-current status of use of digitoxin. Eur J Clin Invest 31 (Suppl 2): 10-17, 2001.

10. Elbaz HA, Stueckle TA, Tse W, Rojanasakul Y and Dinu CZ: Digitoxin and its analogs as novel cancer therapeutics. Exp Hematol Oncol 1: 4, 2012.

11. López-Lázaro M: Digitoxin as an anticancer agent with selectivity for cancer cells: Possible mechanisms involved. Expert Opin Ther Targets 11: 1043-1053, 2007.

12. Xie JW, Chen PC, Zheng CH, Li P, Wang JB, Lin JX, Lu J, Chen QY, Cao LL, Lin M, et al: Evaluation of the prognostic value and functional roles of CD44v6 in gastric cancer. J Cancer Res Clin Oncol 141: 1809-1817, 2015.

13. Buck E, Eyzaguirre A, Brown E, Petti F, McCormack S, Haley JD, Iwata KK, Gibson NW and Griffin G: Rapamycin synergizes with the epidermal growth factor receptor inhibitor erlotinib in non-small-cell lung, pancreatic, colon, and breast tumors. Mol Cancer Ther 5: 2676-2684, 2006.
14. Smith TW: Digitalis toxicity: Epidemiology and clinical use of serum concentration measurements. Am J Med 58: 470-476, 1975.

15. Yan G, Wang Q, Hu S, Wang D, Qiao Y, Ma G, Tang C and Gu Y: Digoxin inhibits PDGF-BB-induced VSMC proliferation and migration through an increase in ILK signaling and attenuates neointima formation following carotid injury. Int J Mol Med 36: 1001-1011, 2015

16. Lin SY, Chang HH, Lai YH, Lin CH, Chen MH, Chang GC, Tsai MF and Chen JJ: Digoxin suppresses tumor malignancy through inhibiting multiple Src-related signaling pathways in non-small cell lung cancer. PLoS One 10: e0123305, 2015.

17. Ha TY, Hwang S, Moon KM, Won YJ, Song GW, Kim N, Tak E, Ryoo BY and Hong HN: Sorafenib inhibits migration and invasion of hepatocellular carcinoma cells through suppression of matrix metalloproteinase expression. Anticancer Res 35: 1967-1976, 2015.

18. Einbond LS, Shimizu M, Ma H, Wu HA, Goldsberry S, Sicular S, Panjikaran M, Genovese G and Cruz E: Actein inhibits the $\mathrm{Na}+\mathrm{K}+-\mathrm{ATPa}$ a and enhances the growth inhibitory effect of digitoxin on human breast cancer cells. Biochem Biophys Res Commun 375: 608-613, 2008.

19. Zhang H, Qian DZ, Tan YS, Lee K, Gao P, Ren YR, Rey S, Hammers H, Chang D, Pili R, et al: Digoxin and other cardiac glycosides inhibit HIF-1alpha synthesis and block tumor growth. Proc Natl Acad Sci USA 105: 19579-19586, 2008.

20. Xu M, Zheng YL, Xie XY, Liang JY, Pan FS, Zheng SG and Lü MD: Sorafenib blocks the HIF-1 $\alpha$ /VEGFA pathway, inhibits tumor invasion and induces apoptosis in hepatoma cells. DNA Cell Biol 33: 275-281, 2014.

21. Pessetto ZY, Weir SJ, Sethi G, Broward MA and Godwin AK: Drug repurposing for gastrointestinal stromal tumor. Mol Cancer Ther 12: 1299-1309, 2013.

22. Woodcock J and Woosley R: The FDA critical path initiative and its influence on new drug development. Annu Rev Med 59: 1-12, 2008

23. Roder C and Thomson MJ: Auranofin: Repurposing an old drug for a golden new age. Drugs RD 15: 13-20, 2015.

24. Kourelis TV and Siegel RD: Metformin and cancer: New applications for an old drug. Med Oncol 29: 1314-1327, 2012.

25. Richards LG, Castle MC and Lage GL: Glucuronidation of digitoxin and its derivatives by rat and rabbit liver homogenates. Drug Metab Dispos 5: 469-473, 1977.

26. Haux J: Digitoxin is a potential anticancer agent for several types of cancer. Med Hypotheses 53: 543-548, 1999.

27. Elbaz HA, Stueckle TA, Wang HY, O'Doherty GA, Lowry DT, Sargent LM, Wang L, Dinu CZ and Rojanasakul Y: Digitoxin and a synthetic monosaccharide analog inhibit cell viability in lung cancer cells. Toxicol Appl Pharmacol 258: 51-60, 2012. 